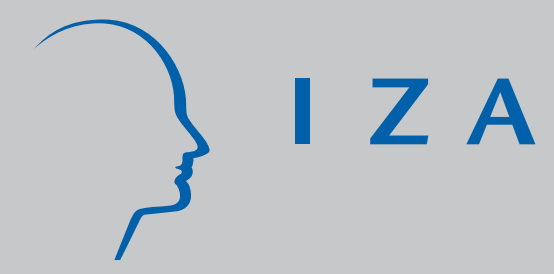

IZA DP No. 4112

Everyone is a Winner: Promoting Cooperation through All-Can-Win Intergroup Competition

Ernesto Reuben

J ean-Robert Tyran

April 2009 


\title{
Everyone is a Winner: Promoting Cooperation through All-Can-Win Intergroup Competition
}

\author{
Ernesto Reuben \\ Northwestern University \\ and IZA \\ Jean-Robert Tyran \\ University of Copenhagen \\ and CEPR
}

Discussion Paper No. 4112

April 2009

IZA

P.O. Box 7240

53072 Bonn

Germany

Phone: +49-228-3894-0

Fax: +49-228-3894-180

E-mail: iza@iza.org

Any opinions expressed here are those of the author(s) and not those of IZA. Research published in this series may include views on policy, but the institute itself takes no institutional policy positions.

The Institute for the Study of Labor (IZA) in Bonn is a local and virtual international research center and a place of communication between science, politics and business. IZA is an independent nonprofit organization supported by Deutsche Post Foundation. The center is associated with the University of Bonn and offers a stimulating research environment through its international network, workshops and conferences, data service, project support, research visits and doctoral program. IZA engages in (i) original and internationally competitive research in all fields of labor economics, (ii) development of policy concepts, and (iii) dissemination of research results and concepts to the interested public.

IZA Discussion Papers often represent preliminary work and are circulated to encourage discussion. Citation of such a paper should account for its provisional character. A revised version may be available directly from the author. 
IZA Discussion Paper No. 4112

April 2009

\section{ABSTRACT \\ Everyone is a Winner: Promoting Cooperation through All-Can-Win Intergroup Competition ${ }^{*}$}

We test if cooperation is promoted by rank-order competition between groups in which all groups can be ranked first, i.e. when everyone can be a winner. This type of rank-order competition has the advantage that it can eliminate the negative externality a group's performance imposes on other groups. However, it has the disadvantage that incentives to outperform others are absent if groups perform at the same level and it therefore does not eliminate low-cooperation equilibria. We find that all-can-win competition produces a universal increase in cooperation and benefits a majority of individuals if incentives to compete are strong.

JEL Classification: H41, M52, C92

Keywords: intergroup competition, cooperation, public goods, experiment

Corresponding author:

Ernesto Reuben

Northwestern University

Kellogg School of Management

2001 Sheridan Rd.

Evanston, IL 60208

USA

E-mail: ereuben@northwestern.edu

\footnotetext{
* We gratefully acknowledge financial support by the Danish Science Foundation (FSE), under Project "Cooperation and Institutions".
} 


\section{Introduction}

Teamwork is often beset with the notorious free-rider problem, and promoting cooperation within teams is therefore a key governance issue in a broad range of organizations. Because of its importance, a considerable literature in experimental economics has investigated the effectives of alternative institutions in promoting cooperation within one team. ${ }^{1}$

This paper is concerned with promoting cooperation within teams by introducing competition between a set of intrinsically independent teams. A wellknown example is the use, by J. Robert Oppenheimer, of competing teams to motivate scientists in Los Alamos during the Manhattan Project (Gosling, 1999). Large automobile companies sometimes let several teams compete when developing the design of a new car. Our mechanism is based on penalizing underperforming teams rather than rewarding the best-performing team. While the incentive mechanism we propose is rather unpleasant for team members as only negative incentives (punishments) are used, it is more pleasant than other competition schemes in other respects. In particular, our mechanism reduces the potentially demoralizing effect of competition because teams can avoid sanctions altogether by exerting high effort and allows for avoiding the negative externality a winning team imposes on other teams.

Laboratory experiments are an excellent tool to study intergroup competition due to a high degree of control over important parameters. ${ }^{2}$ Various researchers have therefore used experiments to demonstrate, for example, that intergroup competition can promote cooperation in social dilemmas (Bornstein et al., 1990; Bornstein and Erev, 1994; Nalbantian and Schotter, 1997; van Dijk et al. 2001), and can facilitate coordination on Pareto-dominant equilibria in coordination games

\footnotetext{
${ }^{1}$ Examples include communication (e.g., Isaac and Walker, 1988), peer pressure (e.g., Fehr and Gächter 2000), tax and subsidy mechanisms (Falkinger et al. 2000), redistribution (Sausgruber and Tyran, 2007), and leadership (Levati et al. 2007).

${ }^{2}$ For instance, experiments allow us to isolate the various channels though which group competition affects cooperative behavior. A good example is Tan and Bolle (2007) who disentangle the effect of monetary incentives versus the effect of simply observing the performance of another group.
} 
(Bornstein et al., 2002; Riechmann and Weimann, 2008). However, to the best of our knowledge, experimental work on intergroup competition has focused on competition schemes in which there can be only one winning group, which implies that contributing towards your group necessarily harms the groups you are competing with.

Although a large number of situations are well-described by this type of intergroup competition (e.g., firms fighting for market share), many cases do not possess the characteristic of "I win, you lose". For example, teams within a firm might be penalized if they fall behind the performance of others, but if all teams perform equally well, no punishment is meted out-that is, everyone wins. In this paper, we study the effectiveness of this type of all-can-win intergroup competition for promoting cooperation in social dilemmas.

All-can-win intergroup competition has an important disadvantage as a mechanism for the promotion of within-group cooperation. Namely, it makes it an equilibrium for all groups to cooperate at the same level, irrespective of how high this level is. In other words, this competition scheme does not eliminate equilibria in which all teams have the same low level of cooperation, which makes it theoretically unclear whether it can successfully promote cooperative behavior.

All-can-win intergroup competition does have the advantage that it reduces the negative externality of own-group production on the earnings of other groups. This can be important as the possibility of hurting others and have others hurt you can crowd out motivations such as positive reciprocity and altruism (Gächter and Fehr, 2002; Fehr and Rockenbach, 2003). ${ }^{3}$ Großer and Sausgruber (2005) show that such crowding out is present in intergroup competition and that competition discourages pro-social individuals from cooperating. With all-can-win competition, if groups are in a situation in which nobody is losing, prosocial individuals have no reason to stop cooperating. Our mechanism relies on penalizing under-performing groups, but sanctions can be avoided altogether by providing high performance.

\footnotetext{
${ }^{3}$ For an extensive review of monetary incentives and the crowding out of pro-social behavior see Frey and Jegen (2001).
} 
The literature on intergroup competition has mainly found that competition promotes cooperation (for an excellent summary see Bornstein, 2003). However, recent studies have also found that with repetition the gains from competition can be small (Tan and Bolle, 2007) or non-existent (Großer and Sausgruber, 2005). These studies suggest that, by and large, competition is beneficial when full cooperation is a Nash equilibrium. To explore the effect of a full-cooperation equilibrium in the case of all-can-win competition, we run two treatments in which full cooperation is supported in equilibrium and a treatment where it is not.

The paper is organized as follows. In section 2 we describe the experimental design and discuss the theoretical differences between treatments. In section 3 we present the results, and in section 4 we conclude.

\section{The experiment}

The experiment consists of two parts, each lasting 10 periods. In part 1, participants play a standard linear public goods game in groups of $n$ subjects (Isaac et al., 1984). In each period, subjects receive an endowment $y=20$ and decide how much of it they want to keep and how much they want to contribute to their group's output. Period earnings are determined by $\pi_{i}=y-c_{i}+\alpha \sum_{j} c_{j}$, where $c_{i}$ is subject i's contribution to group output and $\alpha$ is the marginal per-capita return of group production. In all treatments, $\alpha<1$ and $n \alpha>1$, ensuring both an individual incentive to free ride and an efficiency gain from cooperation. In part 1, under the assumption that all players are own-payoff maximizers, the unique subgame-perfect Nash equilibrium is for all subjects to keep their entire endowment.

In part 2, competition between $K$ groups is introduced. In each period, groups are ranked according to their total contributions and groups that are not ranked $1^{\text {st }}$ have their earnings reduced-with the reduction (weakly) increasing with their distance to $1^{\text {st }}$ place. Specifically, a group's ranking is given by: $1+$ number of other groups with strictly higher contributions. ${ }^{4}$ In other words, in all-can-win

\footnotetext{
${ }^{4}$ This type of ranking is used in, for example, in Olympic sports in which ties are not broken.
} 


\begin{tabular}{cccccccccc}
\hline \hline & & \multicolumn{3}{c}{ Number of } & \multicolumn{1}{c}{$f\left(r_{k}\right)$ for different values of $r_{k}$} \\
Treatment & MPCR & Group Size & groups & & & & & \\
& $\alpha$ & $n$ & $K$ & 1 & 2 & 3 & 4 & 5 \\
\hline T1 & 0.40 & 4 & 5 & 1.00 & 0.80 & 0.60 & 0.40 & 0.20 \\
T2 & 0.50 & 3 & 5 & 1.00 & 0.50 & 0.50 & 0.50 & 0.50 \\
T3 & 0.50 & 3 & 5 & 1.00 & 0.95 & 0.90 & 0.85 & 0.80 \\
\hline \hline
\end{tabular}

competition, groups that contribute the same amount share the same rank. Thus, unlike in other intergroup competition schemes, we allow for more than one winner. In fact, if all groups contribute equally, all groups are ranked $1^{\text {st }}$ and no group is penalized.

The penalty for not being ranked $1^{\text {st }}$ is given the function $f\left(r_{k}\right)$, which transforms group $k^{\prime}$ s rank, denoted $r_{k}$, into a number less than or equal to one. ${ }^{5}$ Specifically, the earnings of subject $i$ who is member of group $k$ equal $\pi_{i k}=\pi_{i} \times f\left(r_{k}\right)$. In the experiment, we ran three treatments, which we label T1, T2, and T3. Each treatment uses a different $f\left(r_{k}\right)$. The specific parameters used in each treatment are shown in Table $1 .^{6}$

We conducted 3 sessions per treatment. Each session consisted of 5 groups that played individually in part 1 and then competed with each other in part 2. T1 was conducted in the University of St. Gallen with 60 MBA students as subjects. T2 and T3 were conducted at the University of Copenhagen with 45 undergraduate students of various fields each. The experiment was programmed and run with zTree (Fischbacher, 2007), and we used the usual experimental procedures of anonymity, incentivized payments, and neutrally worded instructions (see

\footnotetext{
${ }^{5}$ This kind of intergroup competition scheme is used in the production of broiler chicken (Knoeber and Thurman 1994). The principal (a large firm called integrator) subcontracts with smaller firms ("growers") to raise the chicks. The growers are provided with baby chicks and feed by the integrator. The growers deliver the mature chicken to the integrator and are paid according to their relative productivity. That is, growers who used less feed per pound of chicken get a higher price per pound. ${ }^{6}$ In table 1 one can also see that the MPCR and the group size vary between T1 on the one hand and T2 and T3 on the other hand. The reason is that T1 was run in St. Gallen whereas T2 and T3 were run in Copenhagen, and in Copenhagen, due to space and time constraints, it was not possible to use 20 subjects per observation.
} 
appendix for sample instructions). Overall, 150 subjects participated in our experiment, and they earned US $\$ 23.75$ on average.

\subsection{Theoretical predictions}

In this subsection, we briefly discuss the equilibria that emerge when all-can-win competition is introduced. We focus on equilibria in the one-shot version of the game. Furthermore, we highlight the theoretical differences between the treatments.

We start by discussing symmetric equilibria. Namely, Nash equilibria in which all competing groups have the same total contributions-although, within groups, individuals could be contributing different amounts. This includes the fulldefection equilibrium, in which nobody contributes to the public good, as well as the Pareto-dominant equilibria discussed later on. These equilibria have the desirable property that all groups are ranked $1^{\text {st }}$ and therefore nobody is penalized. Furthermore, it is in these equilibria that all-can-win competition differs most from the other competition schemes in the literature.

Note that to attain these equilibria, individuals must overcome two coordination problems: one between groups, in which all groups need to coordinate on the same total contributions, and the other within groups, in which individual contributions must be such that their group's total contributions matches that of the other groups. A priori, it is unclear whether subjects will successfully resolve these coordination problems. In this respect, the penalty a group incurs when its ranking is not $1^{\text {st }}$ is particularly important as it determines the loss of miscoordination.

In both $\mathrm{T} 1$ and $\mathrm{T} 2$, groups can incur relatively strong penalties if they miscoordinate. However, the consequences of miscoordination vary between the two treatments. In T1 miscoordination is particularly costly for groups that negatively deviate from a symmetric equilibrium. In this case, a group's ranking changes from $1^{\text {st }}$ to $5^{\text {th }}$ and the earnings of all group members are reduced by $80 \%$. In contrast, positive deviations are not rewarded or penalized at the group level as the group maintains the same ranking. This asymmetry could help groups move up as it is costlier to err on the side of too little contributions. In T2, the penalty for 
negative deviations is less strong, namely $50 \%$. What is more pronounced in T2 is the effect of a group's deviation on the earnings of other groups. If a group negatively deviates from a symmetric equilibrium, it does not affect the earnings of other groups. However, if it deviates positively it does since it changes their ranking from $1^{\text {st }}$ to $2^{\text {nd }}$. In $\mathrm{T} 2$, this change is quite costly as it means a $50 \%$ reduction in earnings. In contrast in T1, it implies a reduction of only $20 \%$. Hence, in T2 uncertainly about the actions of other groups is more pronounced and might be the driving force for groups to coordinate on a high-contribution equilibrium. Compared to the other treatments, miscoordination is less costly in T3. This could be a disadvantage if it produces less coordination. However, if groups in T1 or T2 do not coordinate in spite of the stiff penalty, overall earnings will be strongly reduced, which would not be the case in T3.

A particularly focal set of symmetric equilibria are Pareto-dominant equilibria (Harsanyi and Selten, 1988). These equilibria correspond to the symmetric equilibria where the amount contributed by each group is the highest amount at which individual group members do not have an incentive to switch to zero contributions. ${ }^{7}$ Pareto-dominant equilibria are particularly attractive since they deliver the highest possible in-equilibrium welfare, which gives subjects a good reason to try to coordinate on them.

The strong competition schemes of $\mathrm{T} 1$ and $\mathrm{T} 2$ have the desirable property that they produce a unique Pareto-dominant equilibrium that consists of full cooperation by all subjects in all groups-which is also attractive because it maximizes total welfare and produces no within-group inequality. In contrast, in T3 full cooperation is not an equilibrium. To see why, suppose all individuals fully contribute to the public good. Furthermore, suppose that an individual is considering a unilateral switch from twenty to zero contributions. In both $\mathrm{T} 1$ and $\mathrm{T} 2$, this switch reduces

\footnotetext{
7 Consider the incentives for player $i$ to reduce contributions if all players are in a symmetric equilibrium and, therefore, all groups are ranked $1^{\text {st }}$. If player $i$ reduces his contribution, his group will switch from being ranked $1^{\text {st }}$ to being ranked $5^{\text {th }}$, and therefore, he will only do so if: $f(1) \times\left(y-(1-\alpha) c_{i}+\right.$ $\left.\alpha \sum_{j \neq i} c_{j}\right)<f(5) \times\left(y+\alpha \sum_{j \neq i} c_{j}\right)$.
} 
earnings to the extent that he is better off not switching. ${ }^{8}$ This is not the case in T3 where his earnings would increase slightly from $(20-20+0.5 \times 60) \times 1=30$ to $(20+$ $0.5 \times 40) \times 0.8=32$. In T3, the highest contribution level supported in equilibrium occurs when contributions in all groups equal 40 (67\% of their total endowments). This amount makes coordination between and within groups harder to achieve since there are now numerous Pareto-dominant equilibria, and the majority of them imply within-group differences in cooperation. For example, a group can attain contributions of 40 by having either all its group members contribute 13.3 (which produces no in-group inequality) or by having two group members contribute 20 and one member contribute 0 (which gives the non-contributing member a much higher payoff). Hence, unlike in T1 and T2, the multiplicity of Pareto-dominant equilibria might hinder a group's ability to coordinate on the desired contribution level as each individual might vie for the Pareto-dominant equilibrium that favors them.

Lastly, we shortly mention the existence of asymmetric equilibria-that is, Nash equilibria in which not all groups have the same level of contributions. These equilibria are characterized by miscoordination within a group. We illustrate with an example. It is an equilibrium (in T1 and T2) for four groups to contribute everything and for one group to contribute nothing to the public good. In this case, the non-contributing group receives an incredibly low payoff as it is ranked $5^{\text {th }}$, but since an individual group member cannot change the group's ranking by increasing his contribution, he does not have incentive to do so. However, if all group members could coordinate and simultaneously increase their contribution to twenty, they would all be better off in the Pareto-dominant equilibrium. Treatments differ slightly with respect to asymmetric equilibria. In T2, the one-step change in the penalty as one changes ranking allows for asymmetric equilibria in which a set of groups coordinates in a positive cooperation level and the rest coordinate at zero

\footnotetext{
${ }^{8}$ In T1, the individual's earnings decrease from $(20-20+0.4 \times 80) \times 1=32$ to $(20+0.4 \times 60) \times 0.2=8.8$. In T2, they decrease from $(20-20+0.5 \times 60) \times 1=30$ to $(20+0.5 \times 40) \times 0.5=20$.
} 
cooperation. In T1 and T3, the gradual change in the penalty allows for asymmetric equilibria with up to three cooperation levels.

In summary, in both $\mathrm{T} 1$ and $\mathrm{T} 2$, groups are severely penalized if they miscoordinate. In addition, negative deviations from symmetric equilibria are severely penalized in $\mathrm{T} 1$ and $\mathrm{T} 2$, while positive deviations are not, and full cooperation is supported in equilibrium. These properties of intergroup competition might produce higher cooperation levels in treatments $\mathrm{T} 1$ and $\mathrm{T} 2$ compared to $\mathrm{T} 3$, and compared to the no-competition part. On the other hand, if there is considerable miscoordination so that asymmetric equilibria are common or individuals do not coordinate on an equilibrium at all, T3 might produce higher earnings than T1 and $\mathrm{T} 2$.

\section{Results}

We present the experimental results in the following order. First, we analyze the effect of intergroup competition on mean contributions in all treatments. Second, we focus on the behavior of individual groups. Third, we report how the different competition schemes affect overall earnings.

\subsection{Overall cooperation}

Figure 1 shows the mean contributions to the public good in the three treatments. In periods 1 to 10 subjects play without intergroup competition whereas groups compete in periods 11 to 20 . Table 2 presents the mean contributions for each part and treatment in addition to Spearman's rank correlation coefficients to indicate how contributions evolve over time. As is common in public goods games without competition (Ledyard, 1995), we observe a significant decline in contributions with repetition $(p<0.001)$. We also see in part 1 that average contributions in T1 are 
somewhat lower than those in $\mathrm{T} 2$ and $\mathrm{T} 3 .{ }^{9}$ However, if we do pair-wise comparisons with Wilcoxon-Mann-Whitney tests (WMW), we cannot reject the hypotheses that contributions in all treatments come from the same distribution $(p>$ $0.100) \cdot{ }^{10}$

\footnotetext{
${ }^{9}$ One can expect differences in contributions between $\mathrm{T} 1$ and the other treatments due to differences in the subject pool. In particular, there is evidence that economics and business students tend to be less cooperative (e.g., Marwell and Ames, 1981; Engelmann and Strobel, 2006; Fehr et al., 2006).

${ }^{10}$ We opted for non-parametric tests because the number of observations is small and distributions seem to deviate from a normal distribution (e.g., in the distribution of group means, normality can be rejected in T1 and T2 with Shapiro-Wilk tests, $p<0.05)$. Throughout this section, we apply two-sided test statistics and use group averages across all periods of a part as independent observations. Moreover, when we test the same hypothesis in multiple treatments or when we do pair-wise comparisons, we adjust $p$-values with the method of Benjamini and Hochberg (1995) to minimize the chance of false positives due to multiple testing. This method has an advantage over multiplepopulation tests (e.g., the Kruskall-Wallis test) in that, in addition to controlling for multiple testing, it reveals which are the specific treatment comparisons that drive the significant differences.
} 




Figure 1 - MEAN CONTRIBUtions

Note: The figure shows mean contributions to the public good by treatment. In the first 10 periods groups do not compete whereas in the last 10 periods they do.

As soon as competition is introduced, we see a sharp increase in contributions. Averaging over all ten periods of part 2, contributions increase by a striking $191 \%$ in $\mathrm{T} 1,97 \%$ in T2, and $37 \%$ in T3. Wilcoxon signed-rank tests (WSR) confirm that the change in contributions is statistically significant in all treatments $(p<0.003)$. In addition, in T1 and T2, contributions no longer display a significantly decreasing trend $(p<0.001$ in T1 and $p=0.385$ in T2). In T3, contributions still significantly decrease with time $(p<0.001)$. 


\begin{tabular}{lcccccc}
\hline \hline & \multicolumn{3}{c}{ No Competition } & \multicolumn{3}{c}{ Competition } \\
& $\mathrm{T} 1$ & $\mathrm{~T} 2$ & $\mathrm{~T} 3$ & $\mathrm{~T} 1$ & $\mathrm{~T} 2$ & $\mathrm{~T} 3$ \\
\hline Contributions & & & & & & \\
Mean & 6.33 & 8.83 & 10.00 & 18.40 & 17.36 & 13.69 \\
Time trend (Spearman's $\rho$ ) & -0.44 & -0.39 & -0.39 & 0.39 & 0.07 & -0.30 \\
Earnings & & & & & & \\
Mean & 23.80 & 24.41 & 25.01 & 24.48 & 24.04 & 24.66 \\
Time trend (Spearman's $\rho$ ) & -0.43 & -0.39 & -0.39 & 0.34 & 0.07 & -0.21 \\
\hline \hline
\end{tabular}

Note: For each treatment and part, the table shows for contributions and earnings, the mean over all periods and the value of Spearman's rank correlation coefficient between periods and the respective statistic.

If we compare contributions across treatments in part 2, we find them to be significantly lower in T3 relative to T1 and T2 (WMW tests, $p<0.030$ ). This difference is consistent with the theoretical predictions in the sense that in T3, full contribution by all subjects in all groups is not supported in equilibrium. In fact, it is interesting to see that, on average, contributions in all treatments are fairly close to the Pareto-dominant equilibrium (20.0 in T1 and T2, and 13.3 in T3).

Next, we look at whether intergroup competition increases the contributions of all groups or just of some. We find that, in T1 and T2, competition produces an increase in average contributions in all 15 groups. In T3, average contributions increase in 12 out of 15 groups, they remain constant in 1 group, and decrease in 2 groups. A similar picture emerges if we look at the effect of intergroup competition on individual contributions. In $\mathrm{T} 1$, competition produces an increase in contributions for $98 \%$ of individuals; in T2 for $93 \%$ and in T3 for $80 \%$ of individuals.

In summary, in spite of the fact that groups do not have an incentive to outperform others, intergroup competition results in a large increase in cooperation.

\subsection{Relative performance and cooperation}

The increase in cooperation can also be illustrated by comparing group performance holding ranks constant. That is, we compare the average difference in contributions between groups that are ranked $k^{\text {th }}$ with and without competition. This difference 
can be seen in Figure 2, which shows average contributions by rank for each treatment (see lines with circles). Periods with no competition are displayed in the top part of the figure and periods with competition are displayed in the bottom part.

Without competition, average contributions in T1, T2, and T3 range from 2.0, 2.8 , and 3.7 for groups ranked $5^{\text {th }}$ to $12.6,15.0$, and 17.0 for groups ranked $1^{\text {st }}$ (see right scale in Figure 2). Once competition is introduced, contributions increase at all ranks: average contributions now range from $13.3,9.3$, and 7.3 for groups ranked $5^{\text {th }}$ to 20.0, 20.0, and 19.8 for groups ranked $1^{\text {st. }}{ }^{11}$ Hence, we can conclude that all-canwin intergroup competition produces a universal increase in cooperation.

Nevertheless, since an increase in contributions does not necessarily translate into higher earnings, it is yet unclear whether most groups would find it desirable to compete. In order to guarantee themselves a higher payoff, groups also have to be ranked $1^{\text {st. }}$. Ideally, all groups are ranked $1^{\text {st }}$ and nobody suffers a payoff loss. In other words, we must also take a look at the distribution of rankings.

Figure 2 also contains bar diagrams. The height of the bar shows the average number of groups (across periods) that attained a given rank. For example, the rightmost bar in the bottom left diagram shows that about 3 (out of 5) groups were ranked first in a typical period of treatment $\mathrm{T} 1$ with competition. We can see in the top part of Figure 2 that there is usually one group per rank without intergroup competition in all treatments. In other words, cooperation levels are dispersed absent competition such that, in an average period, one group has the highest cooperation level, another group the second highest, yet another one the third highest, and so on.

\footnotetext{
11 With one exception, the change in cooperation between no competition and competition is statistically significant for all ranks in all treatments (WMW tests, $p<0.022$ for all comparisons except for of groups ranked $2^{\text {nd }}$ in T3 where $p=0.389$ ).
} 
$\mathrm{T} 1$

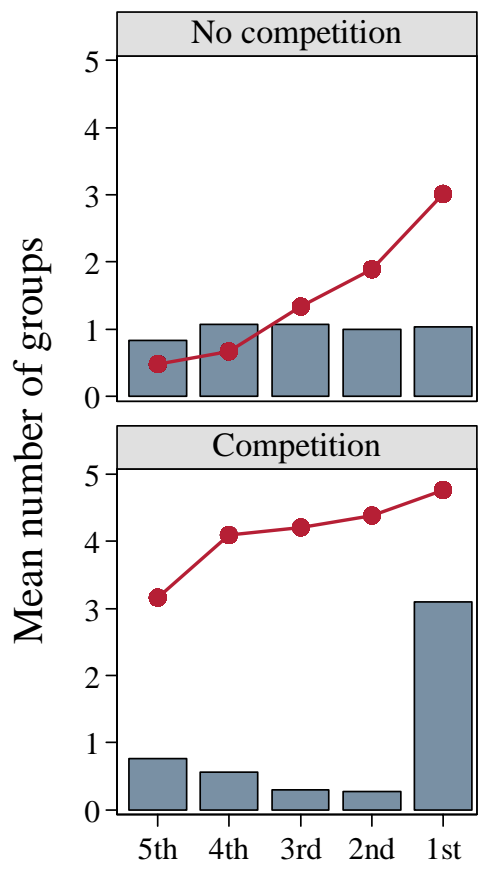

$\mathrm{T} 2$
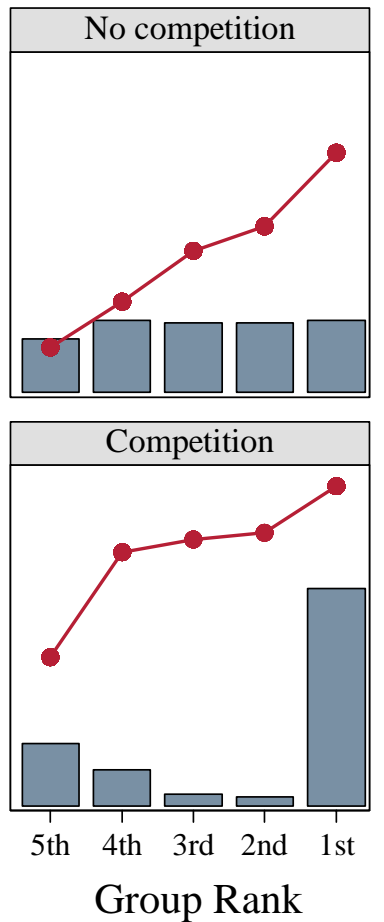

T3

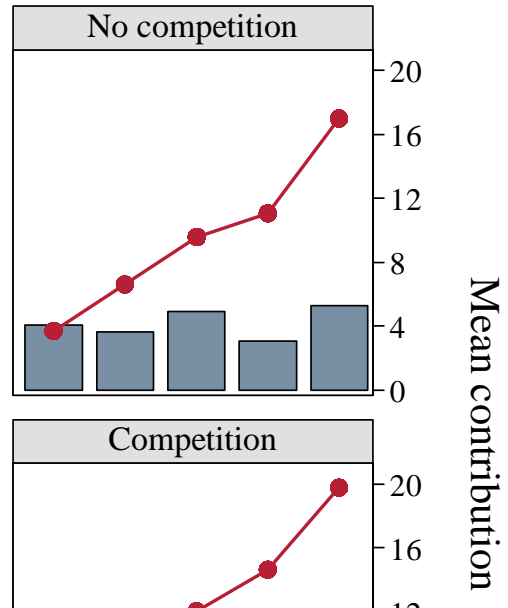

FIGURE 2 - GROUP RANKINGS

Note: The circles (and lines) indicate for each treatment and part, the average contribution to the public good (right-hand axis) depending on the group's rank. The bars show the average number of groups per period (left-hand axis) that attained a given rank. Periods without competition are displayed in the top part of the figure and periods with competition are displayed in the bottom part.

With intergroup competition, the distribution of rankings changes considerably. In particular, there is an increase in the number of groups that are

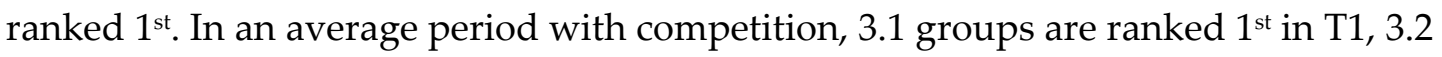
in $\mathrm{T} 2$, and 1.7 in $\mathrm{T} 3$ (up from 1.0, 1.1, and 1.3, respectively). The change in the number of groups that are ranked $1^{\text {st }}$ is statistically significant in $\mathrm{T} 1$ and $\mathrm{T} 2$ but not in T3 (WSR tests, $p<0.007$ in T1 and T2, and $p=0.288$ in T3). The number of groups ranked $1^{\text {st }}$ is even bigger and the differences between $\mathrm{T} 3$ and the other treatments are more pronounced if we consider only periods close to the end. For example, if we look at the last five periods with competition, the number of groups ranked $1^{\text {st }}$ is 3.9 in $\mathrm{T} 1,3.5$ in $\mathrm{T} 2$, and 1.5 in $\mathrm{T} 3$.

This is a remarkable result for T1 and T2 as not only are a substantial number of groups attaining the top rank, they attain it at the maximum cooperation level 
(i.e., at 20.0). This virtually perfect cooperation is consistent with groups trying to coordinate on the Pareto-dominant equilibrium. In T3, competition stimulates contributions but groups fail to coordinate on the same cooperation level. In fact, given that the highest level of contributions supported in equilibrium is 13.3 and that groups ranked $1^{\text {st }}$ are clearly contributing more than this amount, it appears that (some) groups are not even attempting to coordinate on one of the Nash equilibria.

\subsection{Group and individual cooperation}

We now check whether cooperation in periods without competition predicts cooperation in periods with competition. This is important as it allows us to observe whether intergroup competition is robust to preferences for cooperation. In other words, we check whether the increase in contributions is due to groups or individuals who are intrinsically motivated to cooperate or whether those with more selfish preferences also react with higher cooperation. We start the analysis at the group level.

A simple way of observing whether relatively cooperative groups remain cooperative once intergroup competition is introduced is to look at the correlation between the groups' average ranking with and without competition. In T1, Spearman's correlation coefficient between these two variables is $\rho=0.25(p=0.547)$. In T2 it is $\rho=0.15(p=0.595)$, and in T3 it is $\rho=0.74(p=0.005)$. Hence, in both T1 and T2, cooperativeness without competition is not a good predictor of cooperation with competition, unsurprisingly perhaps, as competition increases contributions in all groups to very high levels. The opposite is true for T3. In this treatment, a group's ranking with no competition is an excellent predictor of the group's ranking once competition is introduced. In other words, competition increases contributions in all groups but does not alter the groups' relative position.

We reach a similar conclusion when considering contributions by individuals. We calculate for each individual in each treatment, group, and period their ranking within the group. Rankings are calculated using the same procedure as for groups. 
We then calculate the correlation between the individuals' average ranking with and without competition. In T1 and T2, Spearman's correlation coefficients are low and not significantly different from zero (for T1 $\rho=-0.09, p=0.509$, and for T2 $\rho=$ $0.15, p=0.477)$. In other words, both cooperative and uncooperative individuals start cooperating substantially with competition in T1 and T2. We think this finding is exciting because it shows that the success of intergroup competition does not rely on the presence of highly motivated cooperators that reliably generate high levels of cooperation. However, the results from T3 remind us that this desirable robustness depends on the proper implementation of incentives for competition (recall that high levels of cooperation are not sustained by an equilibrium in T3). In spite of the increase in contributions in T3, relatively cooperative individuals (within their group) keep on being the most cooperative during periods with intergroup competition $(\rho=0.53, p=0.001) \cdot{ }^{12}$

\subsection{Competition and welfare}

The previous discussion has shown that intergroup competition increases overall contributions in all treatments, and that the effect is particularly strong in T1 and T2. Contributions to the public good are directly proportional to a measure of efficiency, namely, the output produced by all groups. This measure is relevant if we consider how competition improves overall output in a firm, say. However, a more conservative measure of efficiency is to consider the sum effective earnings of participants and treating the sanctions as "waste". This measure is relevant if we ask how much popular support the introduction of competition may enjoy.

We find that intergroup competition has an ambiguous effect on earnings. Average earnings for each treatment and part are shown in Table 2. As can be seen, there is a slight increase in earnings in $\mathrm{T} 1$ and a slight decrease in $\mathrm{T} 2$ and $\mathrm{T} 3$. However, these differences are not statistically significant in any of the treatments (WSR tests, $p>0.100$ ). We do see some differences when we look at how earnings

\footnotetext{
12 Note that we do not find that competition crowds out contributions by 'pro-social' individuals - that is, individuals who are high contributors in the absence of competition.
} 


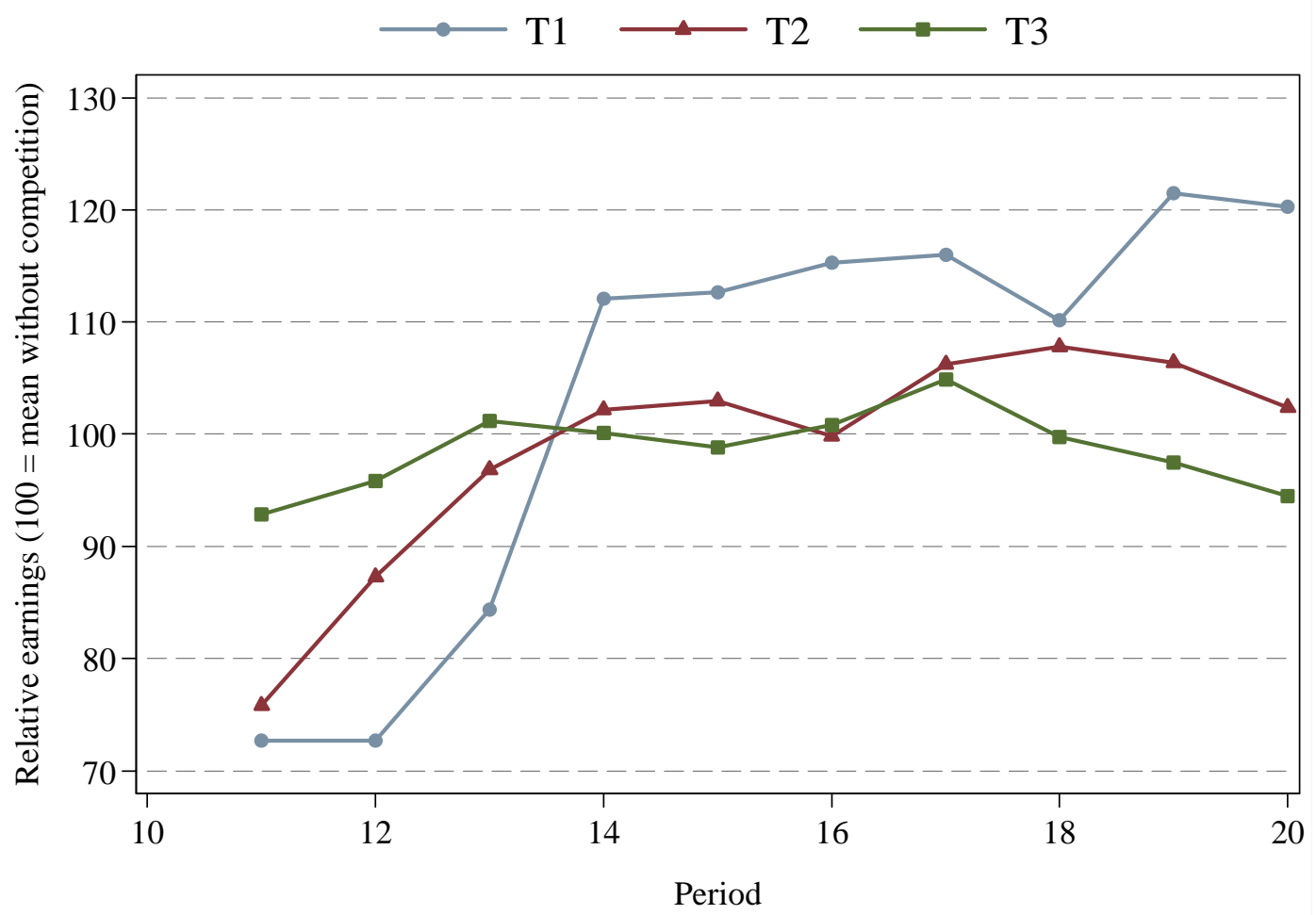

FiguRE 3 - RELATIVE EARNINGS

Note: The figure shows mean earnings for periods with competition as a percentage of earnings in the equivalent period without competition.

change with repetition. Without competition, earnings display a significantly decreasing trend. In contrast, in T1 we find that earnings significantly increase over time $(p=0.001)$ and in T2 they do not show a significant decrease $(p=0.385)$. In T3, it is still the case that earnings exhibit a significantly decreasing trend $(p=0.017)$.

Figure 3 shows average earnings for periods with competition as a percentage of earnings in the equivalent period without competition. As can be seen, in both T1 and T2, earnings with competition are initially well below earnings without competition. However, after three periods, the opposite is true. In T1, the effect is particularly strong. Thus, one could argue that, given enough repetition, competition will eventually produce a positive effect on earnings in $\mathrm{T} 1 .{ }^{13}$ In T2, earnings with competition seem to stabilize at slightly above $100 \%(109 \%$ if we take

\footnotetext{
${ }^{13}$ A similar pattern is seen if one compares public good games without punishment to those with punishment (Fehr and Gächter, 2000). In this case, Gächter et al. (2008) have shown that in the long run punishment does deliver significantly higher earnings.
} 
the last five periods). Therefore, in this treatment it is less clear that earnings with competition will unambiguously surpass those without competition (or at least it will require a much longer time span).

Instead of comparing average earnings, another way of evaluating the welfare effect of intergroup competition is to look at the number of individuals who benefit from it. In T1, averaging across all periods, 42 out of 60 subjects (70\%) earned more with competition and 18 (30\%) earned more without competition. In T2, 25 out of 45 (56\%) earned more and 20 (44\%) earned less, and in T3, 22 out of 45 (49\%) earned more, 22 (49\%) earned less, and 1 (2\%) earned the same amount. Hence, in T1 and $\mathrm{T} 2$, a majority of subjects benefit from competing whereas in $\mathrm{T} 3$ winners and losers are balanced out. If we test whether significantly more subjects benefit from competition than suffer from it, we find that this is the case in T1 but not in T2 and T3 (Sign tests, $p=0.008$ for T1, $p=0.827$ for T2, and $p=1.000$ for T3).

\section{Conclusions}

In this paper, we study the effectiveness of intergroup competition in promoting cooperative behavior. In particular, we focus on intergroup competition in which everyone can be a winner. We report the results of a laboratory experiment where we vary the incentives to compete. We find that intergroup competition produces a universal increase in cooperation. Hence, we find it to be an effective way of increasing overall group output. Furthermore, when incentives to compete are strong, intergroup competition benefits a majority of individuals, albeit it falls short of increasing earnings for every single participant.

The type of intergroup competition considered in this paper does not provide groups a strict incentive to outcompete others. However, in spite of this fact, intergroup competition increased contributions in $93 \%$ of the groups. A systematic effect is present even in the treatment with relatively weak incentives to compete, in which $80 \%$ of the groups increased their average contribution. Thus, for the purpose of increasing group output, all-can-win competition works remarkably well. 
In treatments with strong incentives to compete, intergroup competition generally produced the desired result, that is, many winners and few (or no) losers. Thus, in spite of the multiplicity of equilibria, subjects seem to focus on the Paretodominant equilibrium. With reduced incentives to compete, groups fail to coordinate on the same cooperation level. Interestingly, this miscoordination seems to be due to the fact the highest-paying equilibrium is no longer the Paretodominant outcome. This gives 'naturally' cooperative groups an incentive to deviate from it, as by doing so they can obtain higher earnings. The downside is that groups which are less cooperative are not able to match those contribution levels and thus may be discouraged by constantly losing the competition.

To some extent, the effectiveness of all-can-win competition could be explained by equilibrium concepts that take into account the possibility that individuals make mistakes. In particular, the quantal-response equilibrium (QRE), posits that mistakes are more likely to occur if they are less costly (McKelvey and Palfrey, 1995). As discussed in section 2, if groups are tied in T1 and T2, the payoff loss to an individual of decreasing his contribution is generally bigger than the loss of increasing it. Therefore, QRE predicts that individuals are more likely to err on the side of higher rather than lower contributions, which may induce groups to ratchet up cooperation in these treatments. In T3, this is the case only at low cooperation levels and therefore QRE predicts a smaller effect. Yet, QRE provides no plausible explanation for the very high contributions we observe by some groups in T3-these contribution levels are well outside supported equilibria and would therefore require very frequent mistakes. However, a model that integrates noisy decision making and altruism may narrow this gap (e.g., see Anderson et al., 1998).

The effect of intergroup competition on individual earnings is less straightforward. While a majority of participants and groups benefit from competition if incentives to compete are strong, participants in the few losing groups suffer such a stiff penalty for not winning. To illustrate, we compare the earnings of the best- and worst-performing groups. In T1 and T2, the average earnings of the worst-performing group decrease from 21.8 without competition to 14.2 with competition. In contrast, the earnings of the best-performing group 
increase from 27.0 to 30.4 . In other words, intergroup competition increases the earnings of a majority but strongly reduces those of a minority. As a result, average earnings across all participants are about the same with and without competition in $\mathrm{T} 1$ and T2. When groups compete in treatment T3 with weaker incentives, the penalty for losing is smaller but so are the gains from cooperation, which results again in statistically indistinguishable earnings with and without competition. ${ }^{14}$

In summary, we find that that strong all-can-win competition produces a robust increase in cooperative behavior and can benefit a majority of individuals. However, it also produces a few individuals that are severely disadvantaged.

\section{References}

Anderson, S.P., Goeree, J.K., and Holt, C.A. (1998). A Theoretical Analysis of Altruism and Decision Error in Public Goods Games. Journal of Public Economics 70: 297-323.

Benjamini, Y. and Hochberg, Y. (1995). Controlling the False Discovery Rate: A Practical and Powerful Approach to Multiple Testing. Journal of the Royal Statistical Society Series B (Methodological) 57: 289-300.

Bornstein, G. (2003). Intergroup Conflict: Individual, Group, and Collective Interests. Personality and Social Psychology Review 7: 129-145.

Bornstein, G. and Erev, I. (1994). The Enhancing Effect of Intergroup Competition on Group Performance. International Journal of Conflict Management 5: 271-281.

Bornstein, G., Erev, I., and Rosen, O. (1990). Intergroup Competition as a Structural Solution to Social Dilemmas. Social Behaviour 5: 247-260.

Bornstein, G., Gneezy, U., and Nagel, R. (2002). The Effect of Intergroup Competition on Group Coordination. Games and Economic Behavior 41: 1-25.

\footnotetext{
${ }^{14}$ In this treatment, the difference between worst- and best-performing groups is affected less by competition. With competition, the average earnings of the worst-performing group decrease from 22.5 to 20.3 , and those of the best-performing group increase from 27.6 to 28.9 .
} 
Engelmann, D. and Strobel, M. (2006). Inequality Aversion, Efficiency, and Maximin Preferences in Simple Distribution Experiments: Reply. American Economic Review 96: 1918-1923.

Erev, I., Bornstein, G. and Galili, R. (1993). Constructive Intergroup Competition as a Solution to the Free Rider Problem: A Field Experiment. Journal of Experimental Social Psychology 29: 463-478.

Falkinger, J., Fehr, E., Gächter, S. and Winter-Ebmer, R. (1995): A Simple Mechanism for the Efficient Private Provision of Public Goods - Experimental Evidence. American Economic Review 90: 247-264.

Fehr, E. and Gächter, S. (2000). Cooperation and Punishment. American Economic Review 90: 980-94.

Fehr, E., Naef, M., and Schmidt, K.M. (2006). Inequality Aversion, Efficiency, and Maximin Preferences in Simple Distribution Experiments: Comment. American Economic Review 96: 1912-1917.

Fehr, E. and Rockenbach, B. (2003). Detrimental Effects of Sanctions on Human Altruism. Nature 422: 137-140.

Fischbacher, U. (2007). z-Tree: Zurich Toolbox For Ready-Made Economic Experiments. Experimental Economics 10: 171-178.

Frey, B.S. and Jegen, R. (2001). Motivation Crowding Theory. Journal of Economic Surveys 15: 589-611.

Gächter, S. and Fehr, E. (2002). Do Incentive Contracts Undermine Voluntary Cooperation? Working Paper No. 34, University of Zurich.

Gächter, S., Renner, E., and Sefton, M. (2008). The Long-Run Benefits of Punishment. Science 322: 1510.

Gosling, F.G. (1999). The Manhattan Project: Making the Atomic Bomb. United States Dept. of Energy. History Division.

Großer, J. and Sausgruber, R. (2005). Effort Externalities and Social Norms in the Workplace. Mimeo.

Harsanyi, J.C. and Selten, R. (1988). A General Theory of Equilibrium Selection in Games. Cambridge: MIT Press. 
Isaac, R.M., Walker, J.M., and Thomas, S. (1984). Divergent Evidence on Free Riding: An Experimental Examination of Possible Explanations. Public Choice 43: 113149.

Isaac, R.M., and Walker, J.M. (1988). Communication and Free-Riding Behavior: The Voluntary Contributions Mechanism. Economic Inquiry 26: 585-608.

Knoeber, C.R. and Thurman, W.N. (1994): Testing the Theory of Tournaments: An Empirical Analysis of Broiler Production. Journal of Labor Economics 12: 155179.

Ledyard, J.O. (1995). Public Goods: A Survey of Experimental Research. In Kagel, J.H. and Roth, A.E. (eds.) The Handbook of Experimental Economics pp. 111-194. New Jersey: Princeton University Press.

Levati, V., Sutter, M. and van der Heijden, E. (2007): Leading by Example in a Public Goods Experiment with Heterogeneity and Incomplete Information. Journal of Conflict Resolution 51: 793-818.

Marwell, G. and Ames, R.E. (1981). Economists Free Ride, Does Anyone Else? Experiments on the Provision of Public Goods, IV. Journal of Public Economics 15: 295-310.

McKelvey, R.D. and Palfrey, T.R. (1995). Quantal Response Equilibria for Normal Form Games. Games and Economic Behavior 10: 6-38.

Nalbantian, H.R. and Schotter, A. (1997). Productivity Under Group Incentives: An Experimental Study. American Economic Review 87: 314-341.

Riechmann, T. and Weimann, J. (2008). Competition as a Coordination Device: Experimental Evidence from a Minimum Effort Coordination Game. European Journal of Political Economy 24: 437-454.

Sausgruber, R. and Tyran, J.-R. (2007): Pure Redistribution and the Provision of Public Goods. Economics Letters 95: 334-338.

Tan, J.H.W. and Bolle, F. (2007). Team Competition and the Public Goods Game. Economics Letters 96: 133-139.

Van Dijk, F., Sonnemans, J. and van Winden, F. (2001). Incentive Systems in a Real Effort Experiment. European Economic Review 45: 187-214. 


\section{Appendix - Instructions}

Below we reproduce the instructions used in T3. Instructions for other treatments are available upon request.

\section{General Instructions}

You are now taking part in an economic experiment. Depending on your decisions and the decisions of other participants you can earn a considerable amount of money. How you can earn money is described in these instructions. It is therefore important that you read these instructions carefully.

During the experiment you are not allowed to communicate with other participants in whatever way. If you have any questions please raise your hand. One of us will come to your table to answer your question.

During the experiment your earnings will be calculated in points. At the end of the experiment points will be converted to Danish kroner (DKK) at the following rate:

$$
25 \text { points }=10 \mathrm{DKK}
$$

After the experiment your total earnings from the experiment will be paid out to you anonymously and in cash.

In the experiment, all participants are randomly divided into groups of 3 . This means that you are in a group with two other participants. You will be part of the same group throughout the experiment. Nobody knows which other participants are in their group, and nobody will be informed who was in which group after the experiment.

The experiment today consists of two parts. You will receive detailed instructions of each part of the experiment before the start of the respective part. The following pages describe in detail part one of the experiment. 


\section{Instructions for part one}

\section{Your decision}

The first part of the experiment has 10 periods. In each period, everyone will be given an endowment of 20 points. Then, you and the other group members simultaneously decide how to use the endowment of 20 points. You have two possibilities:

1. You can allocate points to a group account.

2. You can allocate points to a private account.

You have to use your entire endowment in each period. That is, the points you put into the group account and the points you put into the private account have to sum up to 20. You will be asked to indicate the number of points you want to put in the group account. The remaining points will be automatically allocated to the private account.

\section{How to calculate your income}

Your total income depends on the total number of points in the group account, and the number of points in your private account.

Your income from your private account is equal to the number of points you allocated to the private account. For each point you put into the private account you get an income of 1 point. The income of other group members is not affected by the points you allocate to your private account. For example, your income from the private account is 3 points if you put 3 points into it.

Your income from the group account is the sum of points allocated to the group account by all 3 members multiplied by 0.5 . For each point you put into the group account you and all other group members get an income of 0.5 points. For example, if the sum of points in the group account is 24 , then your income from the group account and the income of each other group member from the group account is 12 . 
20 - (points you allocate to the group account) $+0.5 \times$ (the sum of points allocated by all 3 group members to the account)

You get an income of 1 point for each point you allocate to your private account. If you instead allocate 1 extra point to the group account, your income from the group account increases by $1 \times 0.5=0.5$ points and your income from your private account decreases by 1 point. Note that by doing this the income of other group members increases by 0.5 points. Therefore, the total group income increases by $3 \times 0.5=1.5$ points. Other group members therefore also obtain income if you allocate points to the group account. Note that, you also obtain income from points allocated to the group account by other members. You obtain $1 \times 0.5=0.5$ points for each point allocated to the group account by another group member.

\section{Examples}

Suppose you allocate 10 points to the group account, the second member of your group allocates 20 points and the third group member allocates 0 points. In this case, the sum of points on the group account will be 30 points, and all group members get an income of $30 \times 0.5=15$ points from the group account.

Your income in that period is: $(20-10)+15=25$ points.

The second group member's income is: $(20-20)+15=15$ points.

The third group member's income is: $(20-0)+15=35$ points.

\section{Instructions for part two}

In this part of the experiment, everything is the same as in part one, except that your income will be influenced by the "rank" that your group has relative to the other groups.

The ranking is based on the number of points on the group account of your group compared to the other groups. This will be explained in more detail later.

In the experiment there are 5 groups in total. Group composition will be the same as in part one. That is, the two other members of your group will be the same 
as before. Except for the ranking everything is the same. In particular each participant decides how to allocate 20 points in each period as before.

\section{$\underline{\text { How to calculate your income }}$}

Here is an illustration of, how your decision determines your income, note that it is the points allocated to the group account by all members that determine the rank of the group.

Your decision $\rightarrow$ Points in the group account $\rightarrow$ Rank $\rightarrow$ Conversion $\rightarrow$ Income

Your decision, that is, the number of points you allocate to the group account, influences the total number of points on the group account. The total number of points on the group account determines the rank of your group. The rank determines the conversion factor. The conversion factor influences all your period's income.

Your income in points

[ 20 - (points you allocate to the group account) $+0.5 \times$ (the sum of points allocated by all 3 group members to the account) ] $\times$ conversion factor

The size of the conversion factor, is determined by the points allocated to your group account compared the group account of other groups. Note that all of your income is multiplied by the conversion factor.

For a given contribution, the higher the conversion factor of your group, the higher your income. The group with the highest number of points on the group account is assigned rank 1, which means that this group gets the highest conversion factor of 1.0. The group with the second highest number of points on the group account is assigned rank 2, which means that this group gets a conversion factor of 0.95, and so on. The conversion factor for a given rank is given in the following table.

\begin{tabular}{cc}
\hline \hline Rank & Conversion factor \\
\hline 1 & 1.00 \\
2 & 0.95 \\
3 & 0.90 \\
4 & 0.85 \\
5 & 0.80 \\
\hline \hline
\end{tabular}


If more than one group contributes the same number of points to the group account, then they get the same conversion factor. For example if all groups have the same number of points in the group account, they all have the same rank (that is, rank 1) and the same conversion factor (that is, 1.00).

If two groups are ranked 1, the group with the third highest number of points in the group account will have the rank 3 and a conversion factor of 0.90 (see table below).

Examples

\begin{tabular}{cccc}
\hline \hline Group number & $\begin{array}{c}\text { Number of points in the } \\
\text { group account }\end{array}$ & Rank & Conversion Factor \\
\hline 1 & 29 & 3 & 0.90 \\
2 & 32 & 1 & 1.00 \\
3 & 32 & 1 & 1.00 \\
4 & 29 & 3 & 0.90 \\
5 & 11 & 5 & 0.80 \\
\hline \hline
\end{tabular}

Suppose you are a member of group 1 and suppose you have allocated 10 points to the group account, suppose the other two members allocated 19 points in total. In this case the sum of points on the group account is 29 , and the rank of your group is 3 . The conversion factor of your group is 0.90 . As a consequence your income is: $(20-10+0.5 \times 29) \times 0.90=22.05$ points.

Now, suppose you are a member of group 2 and suppose you have allocated 0 points to the group account, suppose the other two members allocated 32 points in total. In this case the sum of points on the group account is 32 , and the rank of your group is 1. The conversion factor of your group is 1.00. As a consequence your income is: $(20-0+0.5 \times 32) \times 1.00=36$ points.

As a further example, suppose you are a member of group 5 and suppose you have allocated 11 points to the group account, suppose the other two members allocated 0 points in total. In this case the sum of points on the group account is 11 , and the rank of your group is 5 . The conversion factor of your group is 0.80 . As a consequence your income is: $(20-11+0.5 \times 11) \times 0.80=11.6$ points. 